\title{
EVALUATION OF PWA1483 FOR LARGE SINGLE CRYSTAL IGT BLADE APPLICATIONS
}

\author{
Dilip M. Shah and Alan Cetel \\ M/S114-43, Pratt \& Whitney \\ 400 Main Street, E. Hartford, CT 06033
}

\begin{abstract}
As a part of the Department of Energy "Land Based Turbine Casting Initiative" program, a high chromium containing, corrosion resistant single crystal alloy, PWA1483, was evaluated for large single crystal component application in industrial gas turbines (IGT). The objective of the program was to assess the impact of casting size on casting yield and structural performance of a large anisotropic body. For this purpose, large single crystal blades cast at two different growth rates, were evaluated for crystallographic quality, microstructure, and high angle boundary (HAB) type defects. Presence of HAB defects, is one of the principal factors, contributing to casting rejection. Testing consisted of $649^{\circ} \mathrm{C}$ tensile, and $760^{\circ} \mathrm{C}, 871^{\circ} \mathrm{C}$, and $982^{\circ} \mathrm{C}$ creep, as a function of the deviation of the tensile direction from $<001\rangle$. PWA1483 bicrystals were cast, and tolerance to HAB was evaluated in creep at $760^{\circ} \mathrm{C}$ and $982^{\circ} \mathrm{C}$. To assess the potential benefit of minor element additions on $\mathrm{HAB}$ tolerance, single crystals and bicrystals of hafnium and boron modified PWA1483 were also evaluated.
\end{abstract}

The results show a linear decrease in tensile strength, and creep rupture life, and a corresponding increase in tensile elongation, with increasing deviation from $\langle 100\rangle$. As expected, for the single crystal alloy PWA1483, with no minor elements, a precipitous drop in creep capability occurred, when grain boundary misorientation exceeded $10^{\circ}$. However, in the modified PWA1483, with deliberate additions of hafinium and boron, surprisingly, there was no significant drop in creep-strength even with grain boundary misorientation as high as $25^{\circ}$. The potential role of other factors, in this unexpectedly high tolerance to $\mathrm{HAB}$ of the modified alloy, is discussed further. Overall, the results provide a good basis for determining tradeoffs between, tensile strength, temperature capability, and grain boundary tolerance, vis-a-vis potential increase in casting yields with improvement in casting technology.

\section{Introduction}

The objective of this effort was to support a broad program to assess and address the potential technical and economic barriers in transitioning single crystal technology to large industrial gas turbine (IGT) components. Among a variety of associated issues, single crystal casting acceptance standards and post-casting processing, were considered two major factors affecting casting yield and design performance of large components. Discussion in this paper will be primarily focused on the factors influencing casting acceptance standards.

\section{Casting Acceptance Standards}

Mechanical and physical properties of components cast in equiaxed polycrystalline nickel base superalloys can be assumed to be isotropic for all practical purposes, when the best conventional casting practice is used. Directionally solidified (DS) components with a columnar grain structure can be treated as transversely isotropic, with no variation of properties in the plane nomal to the growth direction. Here, the superior creep resistance and low modulus, parallel to the columnar grain, are well exploited when the component is DS along the stacking line of interest. However, a single crystal component is truly an anisotropic body, with significant variation in properties along different directions conforming to the crystal symmetry. To take optimum advantage of single crystal properties, control of crystallographic orientation with respect to the part geometry is required.

The additional orientation control is the price one has to pay to exploit the benefits stemming from the elimination of all grain boundaries. Consequently, it must also be assured that the objective of the removal of all grain boundaries is adequately achieved. Any inadvertent presence of HAB must be detected and quantified. Minor low angle boundaries (LAB), are acceptable when they result in no significant loss in performance.

To achieve optimum performance with single crystal nickel base superalloys, the grain orientation with respect to the part geometry, and the tolerance of the material to HAB type defects, must be specified and controlled within limits.

\section{Crystallographic Characterization}

While crystallographic control specifications are well in place for components currently used in aircraft or aeroderivative engines, a re-examination of the practice was deemed necessary, for heavy frame turbines, due to the 2-3X size increase of single crystal castings. The inevitable increase in total number of defects and variation in properties with increasing component volume, imparts additional cost and performance penalties. Furthermore, these issues must be addressed in the context of an altered operating scenario in which long term steady state durability is

Superalloys 2000 
more critical than the number of start-up and shutdown cycles. Specific design of the components enters the picture as well. There is limited engine experience with large single crystal components. An iterative approach with emphasis on crystallographic characterization and property evaluation is necessary to achieve the most cost-effective transition of single crystal technology.

\section{Anisotropy of Physical and Mechanical Properties}

For nickel base superalloys, with cubic structure, physical properties such as thermal expansion and thermal conductivity are isotropic and do not vary with crystallographic direction. Elastic modulus on the other hand, being a fourth rank tensor can be anisotropic, and it does vary significantly with crystallographic orientation in nickel base alloys [1,2]. However, it is largely insensitive to specific alloy composition. In contrast, though, crystallographic slip dependent plastic properties, such as creep and tensile strength are not only anisotropic, but the extent of anisotropy is a strong function of alloy composition

Tensile Properties: There is ample evidence in the literature [1,3, 4] to suggest that tensile properties show significant anisotropic behavior. This variation is rooted in the competition between octahedral and cube slip behavior and therefore is also a complex function of $\gamma^{\prime}$ size and alloy composition. The role of primary orientation, and dendrite splaying if any, on tensile properties must be recognized. From the turbine blade design standpoint, low temperature $\left(-649^{\circ} \mathrm{C}\right)$ tensile properties and associated low cycle fatigue (LCF) life are most critical, for the durability of the root attachment.

Creep Resistance: Long term creep resistance is a life limiting factor for airfoils employed in heavy frame turbines for power generation, which undergo fewer start-up and shutdown cycles than aircraft engines. High temperature creep resistance in single crystal superalloys depends on a complex diffusion controlled slip-climb mechanism, which is highly sensitive to alloy composition. Not only is creep strength, for a given crystallographic orientation, composition sensitive, but the orientation dependence of creep strength can also vary significantly with alloy chemistry. Both major $[1,5]$ and minor elements [6] can alter the nature of creep anisotropy.

The nature of creep anisotropy has important implications for large single crystal castings. In the current design system, variation in properties along the principal loading directions, must be accounted for. In addition, potential increases in spatial variability in primary orientation (splaying) must be considered as well. This is tied into the state of the art of casting technology, and economic viability of process modifications such as seeding. To maximize the future efficient application of large single crystal components, it will be necessary to understand the three dimensional aspects of loading. Understanding the nature of anisotropy will be a first step in that direction.

\section{Effect of the High Angle Boundaries on Mechanical Properties}

One of the principal motivations for pursuing directional solidification was the elimination of grain boundaries, normal to the principal stress direction. Successful application of columnar grain Mar M200 (PWA 1422), required addition of hafnium (Hf) to maintain transverse strength. The maximum benefit of single crystal application occurred when all grain boundary strengthening elements were reduced to sufficiently low levels that segregation was decreased. A concomitant increase in incipient melting point allowed greater latitude in alloy design and solution heat treatment. It is important to recognize that alloys developed specifically for single crystal application are not tolerant to the presence of grain boundaries, especially under creep conditions. Yet from an engineering standpoint, given the complexity of investment casting, the inadvertent presence of low angle boundaries must be tolerated to maintain an economically viable casting yield.

The critical question is what level of grain boundary misorientation or low angle boundary (LAB), can be tolerated without any significant loss in mechanical performance. The misorientation in its simplest form is quantified as the minimum angle of rotation necessary to bring the crystallographic frame of reference in one grain to map on that of the second grain. Owing to cubic symmetry, 24 axes of rotation can be identified, but only one yields a minimum angle. If necessary, the mismatch angle can be separated into its twist and tilt components, but that requires knowledge of the orientation of the grain boundary with respect to the crystallographic frame of reference in one of the grains. However, the added characterization is of marginal value. Typically it is known that grain boundaries with misorientations beyond $10^{\circ}$ result in a precipitous drop in creep-strength. It is interesting to note, that this is approximately the misorientation limit, beyond which grain boundaries can no longer be treated in terms of a dislocation network, and consequently resulting in an order of magnitude increase in diffusion compared to that expected transgranularly [7]. This correlation is another strong indication supporting the view that environmental interaction is a principal factor contributing to the lack of grain boundary ductility.

One of the obvious options to improve the grain boundary tolerance of single crystals, is to add a limited amount of grain boundary strengthening elements, and assess the trade-off between increases in casting yield and corresponding loss in high temperature performance.

For this study, PWA1483, a high chromium containing, single crystal alloy, specifically developed for IGT application was selected for evaluation. Large single crystal IGT blades were cast at two different growth rates, and were evaluated for orientation variability and low angle boundary type defects. The results showed little influence of growth rate on primary orientation. However, a reduction in the population of grain boundary defects was observed in crystals grown at the high growth rate.

The property characterization consisted of tensile $\left(649^{\circ} \mathrm{C}\right)$, and creep $\left(760,871\right.$, and $\left.982^{\circ} \mathrm{C}\right)$ properties as a function of orientation. To assess the tolerance of PWA1483 to low angle boundaries, bicrystals of known orientation were cast and evaluated in creep. To assess the potential benefit of minor element additions on high angle boundary tolerance, single crystal and bicrystal castings of hafnium and boron modified PWA1483 were also evaluated. 
The results show a linear decrease in tensile strength, and creep rupture life, accompanied by an increase in tensile elongation, with increasing deviation from $\langle 100\rangle$. As expected, for the single crystal alloy PWA1483, containing no minor elements, a precipitous drop in creep strength occurred, when grain boundary misorientation exceeded $10^{\circ}$. However, in the modified PWA1483, with deliberate additions of hafnium and boron, no significant drop in creep-strength was observed, even with grain boundary misorientations as high as $25^{\circ}$. This was one of the most interesting findings of this evaluation. Broadly the results provide a good basis for determining tradeoffs between, tensile strength, temperature capability, grain boundary tolerance, and potential reduction in casting rejects, with improvement in casting technology.

\section{Experimental Procedure}

For this study, PWA1483 with $12 \%$ chromium, and a modification with hafnium and boron additions, were selected for evaluation. PWA1483 was specifically developed for marine and industrial gas turbine applications, requiring superior hot corrosion resistance. The advanced single crystal alloy PWA1484 was used for benchmarking casting yield in large components only. Nominal compositions for the three alloys are listed in Table I. The material procured for this study was cast by Howmet Corporation. Chemical analysis of all castings confirmed that the concentration of all elements but boron, was within $2 \%$ of the nominal. Boron was analyzed to be consistently higher than the nominal target of 0.008 weight $\%$, and varied between 0.0098 and 0.018 weight $\%$.

To benchmark casting behavior in large components, Siemens' large V84.4 blade tooling was used. Six large single crystal blades of PWA1483 and PWA1484 each, were cast in 2 molds at two different growth rates, differing by a factor of three. Maximum dimensions of these blades are approximately $21 \times 14$ $\mathrm{x} 4 \mathrm{~cm}$.

Single crystal test material was variously cast as $15.9 \mathrm{~mm}$ and $25.4 \mathrm{~mm}$ diameter bars and $25.4 \mathrm{~mm}$ thick slabs. Molds of PWA1483 were obtained in all three configurations, whereas Modified PWA1483 was cast as slabs and large diameter bars.

For the evaluation of off-axis properties and to study the effect of $\mathrm{HAB}$ on mechanical properties, single crystal bars, and bicrystal slabs were cast using nominally $<100>$-oriented seeds. The bicrystal slab casting configuration is shown schematically in Fig. 1. The desired $\mathrm{L} A \mathrm{AB}$ or $\mathrm{HAB}$ misorientation was achieved by rotating one of the seeds, around its axis, relative to the other. Bicrystals were cast, both in PWA1483 and Modified PWA1483 alloys.

PWA1483 single crystal castings received a solution heat treatment (SHT) of $1260^{\circ} \mathrm{C} / 0.5 \mathrm{hr}$ at the casting supplier, as this enhances subsequent grain etching, and facilitates visual inspection of grain boundary type defects. All material received in the as SHT condition was subsequently heat treated at $1079^{\circ} \mathrm{C} / 4 \mathrm{hr}$ to simulate a coating cycle. The Modified PWA1483 alloy was solution heat treated at $1204^{\circ} \mathrm{C}$, to avoid incipient melting, and subsequently given the simulated coating cycle heat treatment. At $1204^{\circ} \mathrm{C}$, only partial $\gamma$ ' solutioning was achieved.

Standard optical and electron metallographic techniques were used to characterize the material. Grain boundary misorientation was quantified using the X-ray Laue determination of the crystallographic orientation of both grains. Based on this information, the misorientation angle was calculated.

All tensile tests were carried out at a strain rate of $0.5 \% / \mathrm{min}$, as per ASTM standard. The tensile testing was carried out at $649^{\circ} \mathrm{C}$, reflecting a measure of root attachment strength. All creep tests were run per ASTM standard E139.

Creep tests were carried out at $760^{\circ} \mathrm{C}, 871^{\circ} \mathrm{C}$, and $982^{\circ} \mathrm{C}$. Based on prior experience, conditions for testing were selected to produce rupture lives of at least 100 hours. In many cases, the stress was iteratively incrcased or decreased, so that the stress for $100 \mathrm{hr}$ rupture life could be defined.

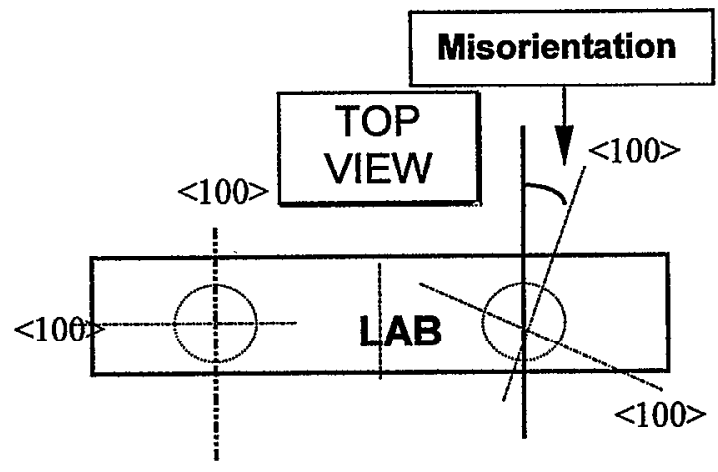

Figure 1: Schematic showing configuration of seeded bicrystal slabs.

Table I Nominal Composition of Alloys Used in P\&W Study.

\begin{tabular}{|c|c|c|c|c|c|c|c|c|c|c|c|c|}
\hline Alloy & \multicolumn{1}{|c|}{ Composition } & Wt. \% & Ta & $\mathrm{Ti}$ & $\mathrm{Al}$ & $\mathrm{Hf}$ & $\mathrm{B}$ & $\mathrm{C}$ \\
\hline & $\mathrm{Ni}$ & $\mathrm{Co}$ & $\mathrm{Cr}$ & $\mathrm{Mo}$ & $\mathrm{W}$ & $\mathrm{Re}$ & $\mathrm{Ta}$ & - & 5.65 & 0.10 & - & - \\
\hline PWA1484 & Bal. & 10 & 5 & 1.9 & 5.9 & 3.0 & 8.7 & - & - & \\
\hline PWA1483 & Bal. & 9.0 & 12.2 & 1.9 & 3.8 & - & 5 & 4.1 & 3.6 & - & - & .07 \\
\hline Modified 1483 & Bal. & 9.0 & 12.2 & 1.9 & 3.8 & - & 5 & 4.1 & 3.6 & 0.5 & 0.008 & .07 \\
\hline
\end{tabular}


$\underline{\text { Results }}$

\section{Cast Microstructure Characterization of Large IGT Blades}

Twelve large single crystal IGT (V84.4) blades were cast in 4 molds, at 2 different growth rates in PWA1483 and PWA1484. The objective of this effort was to assess the quality of single crystal castings, as affected by the casting size, growth rate, and alloy chemistry. Obviously with the small population of castings evaluated, no statistically meaningful conclusions can be drawn, but only major trends in casting quality can be discerned.

Grain defects: In both alloys, the faster growth rate appeared to be beneficial, in that fewer grain boundary type defects were revealed upon macroetching. At the slower growth rate, multiple defects were observed. Moreover, while all 3 blades of PWA1483, were virtually defect free at the faster growth rate, blades cast in PWA1484 were not. No defects were found in PWA1483 blade airfoils, whereas for PWA1484, one airfoil was cracked, and in two cases pits were observed at the tip end. One PWA1484 blade from each mold, showed orientation deviation of as much as $15^{\circ}$ from the primary $<100>$.

Variation in primary orientation or Splaying: Four blades, representing two alloys, and two growth rates in each case, were mapped with Laue X-ray diffraction to determine primary orientation variation, sometimes referred to as splaying. In cach alloy/growth rate group, a blade with the largest deviation in primary orientation was selected, since such orientations have the least crystallographic symmetry. The results indicated virtually no splaying for both alloys at either growth rate. A variation of 2$3^{\circ}$ in primary and secondary orientation is considered natural, as it is comparable to the misorientation between neighboring dendrites. This can be verified using electron channeling pattern (ECP) mapping of dendrite orientation.

$y^{\prime}$ size variation: Blades DS at the fast growth rate, were solution heat treated and sectioned in the root area, tip and mid-span of the airfoil. Optical metallography showed no evidence of under solutioning. To determine the finest $\gamma^{\prime}$ size present in the dendritic core, surface replicas were prepared and examined at high magnification, in a transmission electron microscope. As expected, the average $\gamma^{\prime}$ size was observed to be larger in the massive root area compared to that in the tip area. While the size varied from $\sim 0.29 \mu \mathrm{m}$. to $\sim 0.13 \mu \mathrm{m}$ for PWA1484, less variation $(-0.3 \mu \mathrm{m}$. to $\sim 0.24 \mu \mathrm{m})$ was observed for PWA1483.

Dendritic Sub-structure: In order to discern any correlation between dendritic sub-structure, and rate of solidification, casting size, alloy chemistry, and casting defects; dendritic sub-structure of the available casting configurations was studied.

Surprisingly, the results showed no significant difference in the dendrite density in the large IGT blades cast at growth rates differing by a factor of $3 \mathrm{X}$. The dendritic density was estimated to be around $400 / \mathrm{cm}^{2}$ in the root attachment and decreased to around $300 / \mathrm{cm}^{2}$ in the airfoil. In comparison, the density of dendrites was observed to be higher $\left(550 / \mathrm{cm}^{2}\right)$ in $25.4 \mathrm{~mm}$ thick bars and slabs, and almost a factor of two higher $\left(861 / \mathrm{cm}^{2}\right)$ in the case of $15.9 \mathrm{~mm}$ diameter bars. While the difference in the density of dendrites between $15.9 \mathrm{~mm}$ and $25.4 \mathrm{~mm}$ diameter bars was small, there appeared to be an increased volume of $\gamma / \gamma^{\prime}$ eutectic phase in the latter. Another notable difference was the presence of secondary dendrite arms in Modified PWA1483 castings.

\section{Evaluation of Off-axis Properties}

Off-axis test specimens for tensile, and creep testing were machined from fully heat treated PWA1483, with the orientation of the specimen axis $(\alpha)$ varying from $10^{\circ}$ to $29^{\circ}$ from $\langle 001\rangle$. $\mathrm{X}$-ray Laue data were further analyzed to define the actual crystallographic orientation of the specimen axis, within a standard stercographic triangle. However, the additional information proved academic, as there was insufficient data to discern any trend.

Tensile: All tensile testing was carried out at $649^{\circ} \mathrm{C}$. Average results of four tests originating from a bar with a specific primary orientation $(\alpha)$ are plotted against the primary orientation angle $\alpha$ in Fig. 2. It is apparent hial while $0.2 \%$ yield strength and ultimate tensile strength (UTS) decreases with increasing $\alpha$, the $\%$ elongation increases. It is known that elastic modulus increases with increasing $\alpha$. The results are not surprising, given that in the vicinity of $\langle 001\rangle$, single crystal nickel base superalloys deform by octahedral $\{111\}<110>$ slip, and that strength is controlled by the critical resolved shear strength (CRSS) for the operative slip system. (See Reference 4 for further discussion.) For comparison, the average of duplicate test results for the modified alloy at $6.5^{\circ}$, are also plotted in Fig. 2 .

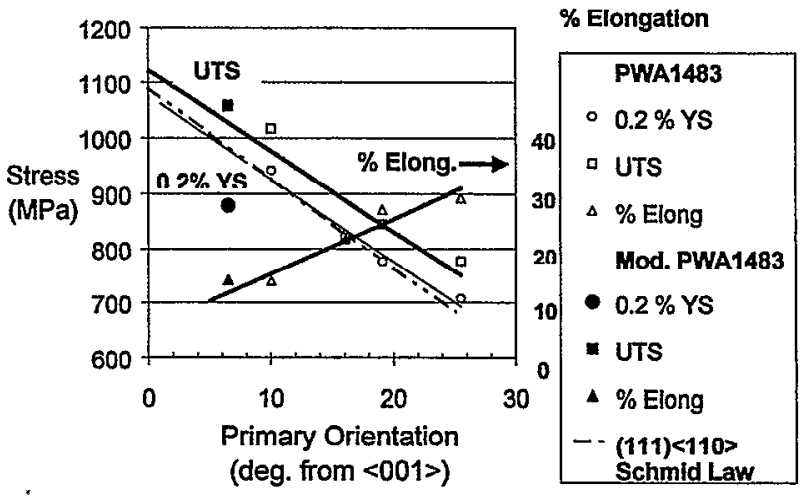

Figure 2: $649^{\circ} \mathrm{C}$ tensile properties of PWA1483, versus primary orientation, measured in $\alpha^{\circ}$ from $<001>$. Results for Mod. PWA1483 are compared at $\alpha=6.5^{\circ}$.

Creep: Off-axis creep behavior of PWA1483 was evaluated at two different stress conditions at $760^{\circ} \mathrm{C}, 871^{\circ} \mathrm{C}$, and $982^{\circ} \mathrm{C}$. A total of 8 bars with different orientations were used. To facilitate a direct comparison of data, at different temperatures and stress combinations, groups of 6 specimens machined from the same bar, with presumably identical orientation, were tested at six different temperature and stress conditions. Thus at a given creep condition (temperature and stress), creep behavior was evaluated for a maximum of 8 different orientations. 
Creep test results at $760^{\circ} \mathrm{C} / 793$ and $655 \mathrm{MPa}, 871^{\circ} \mathrm{C} / 483$ and 345 $\mathrm{MPa}$, and $982^{\circ} \mathrm{C} / 248$ and $172 \mathrm{MPa}$ are presented in Table II. Note that at all test conditions, there is a general tendency of rupture life decreasing with increasing deviation from $<001>$ or angle $\alpha$. Early failure of two specimens at $760^{\circ} \mathrm{C}$, with $\alpha>20^{\circ}$, is attributed to plastic deformation prior to loading, suggesting that in these cases, the stress level may have exceeded the yield strength. Yield strength data presented in Fig. 2, corroborate this conclusion. At $\alpha=25^{\circ}$, the average $649^{\circ} \mathrm{C}$ yield strength was determined to be $113 \mathrm{MPa}$, and it is expected to be similar at $760^{\circ} \mathrm{C}$. This suggests that relaxing the restriction on $\alpha$ beyond $20^{\circ}$, cannot be made without compromising some strength capability. It is also observed that at $760^{\circ} \mathrm{C}$, there is a decrease in total creep ductility with increasing deviation from $<001\rangle$.

\section{Comparison of PWA1483 and Mod. PWA1483 in Creep}

While Mod. PWA1483 was not evaluated extensively in the offaxis orientation, the creep properties were compared with PWA1483, at $\alpha=6 \pm 2^{\circ}$. The creep rupture data at $871^{\circ} \mathrm{C}$ and $982^{\circ} \mathrm{C}$ for both alloys are plotted in Fig. 3. It is clear that, because of under-solutioning to prevent incipient melting with the minor element additions, there is a 5-7 $\mathrm{MPa}$ loss in creep strength for the modified alloy at $871^{\circ} \mathrm{C}$ and $982^{\circ} \mathrm{C}$.

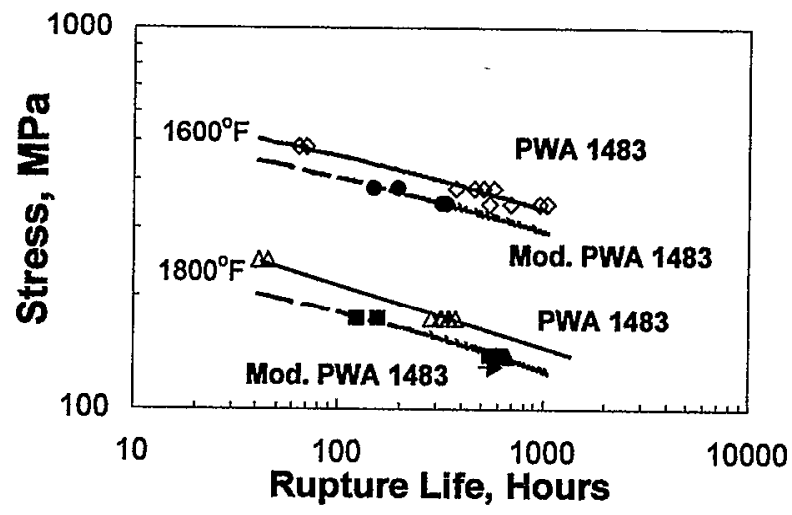

Figure 3: Creep-rupture comparison of PWA1483 and Mod. PWA1483 at $871^{\circ} \mathrm{C}$ and $982^{\circ} \mathrm{C}$.

Table II Creep Test Results of Fully Heat Treated PWA1483 in Off-axis Orientations at $760^{\circ}, 871^{\circ}$, and $982^{\circ} \mathrm{C}$

\begin{tabular}{|c|c|c|c|c|c|c|c|c|c|c|c|c|c|}
\hline $\begin{array}{l}\text { Primary } \\
\text { Orient. }\end{array}$ & Temp. & Stress & $\begin{array}{c}\text { Time to } \\
1 \% \\
\end{array}$ & $\begin{array}{c}\text { Time to } \\
2 \%\end{array}$ & \begin{tabular}{|c|}
$\begin{array}{c}\text { Rupture } \\
\text { Life }\end{array}$ \\
\end{tabular} & Elong. & & Stress & $\begin{array}{c}\text { Time to } \\
1 \% \\
\end{array}$ & $\begin{array}{c}\text { Time to } \\
2 \% \\
\end{array}$ & $\begin{array}{c}\text { Rupture } \\
\text { Life }\end{array}$ & Elong. & \\
\hline$\alpha^{\circ}$ & (C) & (MPa) & (hrs) & (hrs) & (hrs) & $(\%)$ & & (MPa) & (hrs) & (hrs) & (hrs) & (\%) & \\
\hline 10.0 & 760 & 793 & 1.8 & 8.5 & 59.6 & 17.0 & & 655 & 69.0 & 183.0 & 647.2 & 13.4 & \\
\hline 10.2 & 760 & 793 & 1.4 & 7.6 & 46.9 & 12.3 & & 655 & 11.7 & 173.0 & 554.3 & 21.9 & \\
\hline 14.7 & 760 & 793 & 7.9 & 18.8 & 62.8 & 16.4 & & & & & & & \\
\hline 16.2 & 760 & 793 & 8.7 & 21.0 & 61.2 & 12.6 & & 655 & 62.0 & 157.0 & 220.5 & 2.8 & (c) \\
\hline 19.1 & 760 & 793 & 10.7 & 23.0 & 45.6 & 6.0 & & 655 & 79.0 & 160.0 & 384.2 & 9.3 & \\
\hline 19.2 & 760 & 793 & 20.0 & 33.0 & 57.0 & 7.0 & & & & & & & \\
\hline 24.5 & 760 & 793 & 0.1 & 0.2 & 1.1 & 23.5 & (a) & 655 & 78.0 & 153.0 & 223.3 & 3.9 & \\
\hline 26.0 & 760 & 793 & 0.2 & 0.4 & 1.9 & 21.9 & (b) & 655 & 79.0 & 161.0 & 307.8 & 6.4 & \\
\hline 10.0 & 871 & 483 & 9.3 & 151.7 & 69.5 & 18.6 & & 345 & 298.0 & 527.0 & 956.1 & 13.4 & \\
\hline 10.2 & 871 & 483 & 8.2 & 20.0 & 63.9 & 12.7 & & 345 & 377.0 & 591.0 & 1045.7 & 19.4 & \\
\hline 14.7 & 871 & 483 & 10.2 & 22.3 & 65.2 & 20.5 & & 345 & 264.0 & 475.0 & 824.3 & 15.9 & \\
\hline 16.2 & 871 & 483 & 8.6 & 18.7 & 55.7 & 20.0 & & 345 & 258.0 & 497.0 & 877.9 & 19.8 & \\
\hline 19.1 & & & & & & & & 345 & 275.0 & 488.0 & 810.5 & 14.8 & \\
\hline 19.2 & 871 & 483 & 10.7 & 22.3 & 62.4 & 16.0 & & 345 & 392.0 & 586.0 & 859.4 & 19.7 & \\
\hline 24.5 & & & & & & & & 345 & 295.0 & 477.0 & 661.2 & 7.5 & \\
\hline 26.0 & 871 & 483 & 3.1 & 8.1 & 23.4 & 7.6 & & 345 & 301.0 & 466.0 & 656.1 & 7.9 & \\
\hline 10.0 & 982 & 248 & 13.1 & 151.7 & 41.3 & 18.2 & & 172 & 137.0 & 269.0 & 375.9 & 26.6 & \\
\hline 10.2 & 982 & 248 & 18.6 & 27.0 & 45.2 & 15.3 & & 172 & 137.0 & 247.0 & 321.4 & 19.3 & \\
\hline 14.7 & 982 & 248 & 11.0 & 20.6 & 37.5 & 18.4 & & 172 & 188.0 & 228.0 & 266.6 & 14.4 & \\
\hline 16.2 & 982 & 248 & 13.0 & 21.0 & 36.0 & 20.0 & & 172 & 181.0 & 231.0 & 267.1 & 13.4 & \\
\hline 19.1 & 982 & 248 & 24.0 & 31.0 & 43.5 & 15.3 & & 172 & 182.0 & 204.0 & 223.2 & 9.5 & \\
\hline 19.2 & 982 & 248 & 17.6 & 27.0 & 39.7 & 21.3 & & 172 & 168.0 & 206.0 & 244.1 & 17.6 & \\
\hline 24.5 & 982 & 248 & 16.1 & 24.0 & 33.2 & 11.7 & & 172 & 132.0 & 150.0 & 165.6 & 8.4 & \\
\hline 26.0 & 982 & 248 & 15.1 & 23.0 & 32.3 & 13.7 & & 172 & 153.0 & 176.0 & 198.9 & 13.4 & \\
\hline
\end{tabular}
(a) $10.26 \%$ plastic creep on loading.
(b) $8.26 \%$ plastic creep on loading.
(c) discontinued, no failure 
Evaluation of Low and High Angle Boundaries (LAB \& HAB)

A total of twelve (12) bicrystal slabs were cast, six (6) each from PWA1483 and Modified PWA1483. Casting yield for the bicrystals was very poor because of slab geometry, and the targeted grain boundary misorientation angles were not achieved with any precision. For the purpose of this evaluation, the average boundary misorientation measured for each bicrystal casting was assigned to all specimens from the same casting. Grain boundary misorientation of individual specimens was not characterized. A typical macrograph, presented in Fig. 4, confirms that both grain boundary misorientation, and primary orientation, were achieved as intended. Note that from each bicrystal slab, baseline specimens, with no grain boundaries, were always procured. They were machined from one of the two crystals, avoiding the grain boundary.

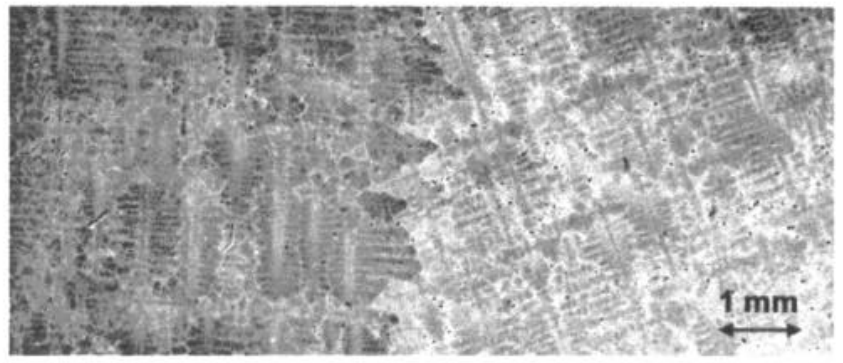

Figure 4: A typical macrograph showing orientation relationship between two grains of a bicrystal specimen.

Creep Strength: The bicrystal specimens were tested in creep at $760^{\circ} \mathrm{C}$, and $982^{\circ} \mathrm{C}$, at various stress levels so that stress for 100 hour rupture could be defined at each temperature for a given alloy. This required lowering the stress for specimens with high angle boundaries. The results for PWA1483 are presented in Table III, and Modified PWA1483 in Table IV. As noted earlier, the Modified PWA1483 alloy was cast with a late addition of 0.5 $\% \mathrm{Hf}$ and $0.008 \% \mathrm{~B}$ to PWA 1483 .

Comparison of data for PWA1483 and Modified PWA1483, clearly show that Modified PWA1483 is much more tolerant to grain boundary type defects. Specifically consider the short rupture life ( 38 and $97 \mathrm{hrs}$ ) of PWA1483 at $760^{\circ} \mathrm{C} / 414 \mathrm{MPa}$ for a $21.2^{\circ}$ boundary. At the identical condition, a specimen of Modified PWA1483 had not ruptured after $4078 \mathrm{hrs}$. This is one of the most interesting findings of this investigation and will be discussed further.

Comparisons of fracture surfaces of creep specimens with and without high angle boundaries, showed a more or less featureless appearance in specimens with no grain boundaries, in contrast to an accentuated dendritic de-cohesion in specimens with high angle grain boundaries. Nonetheless, careful examinations of baseline specimens also revealed inter-dendritic failure. Since the artificially created boundaries in the present cases were largely tilt boundaries, the dendritic pattern was only uni-directional.

\section{Discussion of Results}

\section{Quality of Large Single Crystal IGT Blades}

Effect of Growth Rate: Our observations suggest that it is feasible to DS defect free large single crystal IGT blades at higher growth rates. At appropriate fast growth, not only are high angle grain boundary type defects suppressed, but crystallographic splaying is also virtually absent. However, assessment of how this translates to a large-scale production environment, is beyond the scope of this effort. There is minor influence of alloy chemistry, but no meaningful conclusions can be drawn from this limited study. Based on this study, it appears that PWA1483 is less prone to defects than PWA1484, but the difference is not considered significant. Such small differences can be optimized simply with minor changes in casting process parameters.

Based on our observations, it appears that either the casting technique has achieved considerable maturity, or the massive volume of the part is naturally helpful. Excessive splaying is generally expected in asymmetric parts with undesirable thermal gradients in the plane normal to the growth direction. However, proper clustering of the parts in a mold may mitigate this factor; and a larger mass of material requiring a larger thermal flux, can help flatten out the temperature gradients within the mold.

The Role of Cast Microstructure: To gain some understanding of the interrelationship between cast microstructure, casting process and configuration, and alloy chemistry, dendritic microstructure and sub-structure misorientation were analyzed. Results showed no major differences in dendrite density in blades cast at baseline and at $3 \mathrm{X}$ higher relative growth rate. In fact the $15.9 \mathrm{~mm}$ diameter bars normally used for laboratory evaluation of mechanical properties exhibited distinctly higher dendrite density. In a sense, $25.4 \mathrm{~mm}$ diameter bars more closely simulated the dendritic density of large IGT blades. Another notable difference was the presence of secondary dendrite arms in Modified PWA1483, where melting characteristics were inevitably altered with the addition of boron and hafnium. The presence of secondary arms lead to slightly increased dendrite arm spacing. This was also accompanied by a slight increase in sub-structure misorientation. Based on past experience, this may imply an increased susceptibility to grain boundary type defects, because of less tolerance to transverse thermal gradient. However, a limited comparison of single crystal and bicrystal slabs cast in both alloys did not reveal any strong differences in frequency of grain boundary type defects between the two alloys.

\section{Variation in Off-axis Properties}

Tensile Properties: The $649^{\circ} \mathrm{C}$, tensile data are plotted against the primary orientation angle $\alpha$ in Fig. 2. As expected, while yield strength and UTS decrease with increasing $\alpha$, the $\%$ elongation increases. At low $\alpha$ angle $\left(<15^{\circ}\right)$ the Schmid factor in the vicinity of $<001>$ orientation, for the primary $\{111\}<110>$ slip system can be approximated as $\left(1+0.0149 \alpha^{\circ}\right) / \sqrt{ } 6$. 
Table III $760^{\circ} \mathrm{C}$ and $982^{\circ} \mathrm{C}$ Creep Test Results for PWA1483 Bicrystals

\begin{tabular}{|c|c|c|c|c|c|c|c|c|c|c|c|c|}
\hline $\begin{array}{c}\text { LAB } \\
\text { MISORIENT }\end{array}$ & Temp. & Stress & $\begin{array}{c}\text { Time to } \\
1 \%\end{array}$ & $\begin{array}{c}\text { Time to } \\
2 \%\end{array}$ & $\begin{array}{c}\begin{array}{c}\text { Rupture } \\
\text { Life) }\end{array} \\
\end{array}$ & $\begin{array}{c}\text { Elong. } \\
(\%)\end{array}$ & Temp. & Stress & $\begin{array}{c}\text { Time to } \\
1 \%\end{array}$ & $\begin{array}{c}\text { Time to } \\
2 \%\end{array}$ & $\begin{array}{c}\text { Rupture } \\
\text { Life) }\end{array}$ & Elong. \\
\hline$\left(\right.$ deg. $\left._{2}\right)$ & (C) & (MPa) & (hrs) & (hrs) & (hrs) & $(\%)$ & (C) & (MPa) & (hrs) & (hrs) & (hrs) & $(\%)$ \\
\hline No bound. & 760 & 793 & 5.0 & 21.0 & 106 & 13.7 & 982 & 207 & 70 & 103 & 158.3 & 13.9 \\
\hline No bound. & 760 & 793 & 4.5 & 19.2 & 51.9 & 7.5 & 982 & 221 & 46 & 63.0 & 79.8 & 12.5 \\
\hline No bound. & & & & & & & 982 & 221 & 22 & 50.0 & 97.1 & 16.1 \\
\hline 4.2 & 760 & 690 & 269 & 338 & 499.7 & 10.3 & 982 & 207 & 96 & 134 & 168.2 & 14.8 \\
\hline 4.2 & 760 & 758 & 13.8 & 38.0 & 134.3 & 10.3 & 982 & 207 & 38.0 & 75.0 & 131.8 & 16.2 \\
\hline 4.2 & 760 & 793 & 4.0 & 16.6 & 88.6 & 11.6 & 982 & 221 & 25 & 54.0 & 104.9 & 17.2 \\
\hline 4.2 & 760 & 758 & 6.8 & 26.0 & 110.2 & 9.2 & 982 & 221 & 21.0 & 49.0 & 98.9 & 14.3 \\
\hline 7.6 & 760 & 690 & 17.2 & 53.0 & 67.3 & 2.9 & 982 & 207 & 14.1 & 29.0 & 62.9 & 13.8 \\
\hline 7.6 & 760 & 690 & 18.3 & 50.0 & 249.2 & 21.0 & 982 & 207 & 12.3 & 32.0 & 41.3 & 3.1 \\
\hline 7.6 & 760 & 621 & 61.0 & 175 & 300.8 & 3.6 & 982 & 172 & 62 & - & 117.9 & 2.9 \\
\hline 16.9 & 760 & 414 & - & - & 977.4 & 0.21 & 982 & 207 & & - & 12.7 & 1.60 \\
\hline 16.9 & 760 & 552 & $=$ & $=$ & 6.5 & 0.60 & 982 & 138 & & $=$ & 243.1 & 1.80 \\
\hline 16.9 & 760 & 483 & - & - & 25.4 & 0.28 & 982 & 124 & & - & 227.6 & 0.80 \\
\hline 16.9 & 760 & 483 & $=$ & $=$ & 73.3 & 0.40 & 982 & 138 & & - & 240.7 & 1.0 \\
\hline 21.3 & 760 & 414 & - & - & 38.3 & 0.19 & 982 & 207 & & $=$ & 3.6 & 0.37 \\
\hline 21.3 & 760 & 414 & $=$ & - & 97.4 & 0.70 & 982 & 138 & & - & 58.4 & 0.45 \\
\hline 21.3 & 760 & 345 & $=$ & - & +2034.2 & 0.00 & 982 & 124 & & $\cdots$ & 153.3 & 0.90 \\
\hline 21.3 & 760 & 345 & - & - & 868.1 & 0.5 & 982 & 124 & & - & 420.7 & 0.80 \\
\hline
\end{tabular}

+ Discontinued, no failure

Table IV $760^{\circ} \mathrm{C}$ and $982^{\circ} \mathrm{C}$ Creep Test Results for Modified PWA1483 Bicrystals

\begin{tabular}{|c|c|c|c|c|c|c|c|c|c|c|c|c|}
\hline $\begin{array}{c}\text { LAB } \\
\text { MISORIENT }\end{array}$ & Temp. & Stress & $\begin{array}{c}\text { Time to } \\
1 \%\end{array}$ & $\begin{array}{c}\text { Time to } \\
2 \%\end{array}$ & $\begin{array}{c}\text { Rupture } \\
\text { Llfe }\end{array}$ & Elong. & Temp. & Stress & $\begin{array}{c}\text { Time to } \\
1 \%\end{array}$ & $\begin{array}{c}\text { Time to } \\
2 \%\end{array}$ & $\begin{array}{c}\text { Rupture } \\
\text { Llfe }\end{array}$ & Elong. \\
\hline (deg.) & (C) & (MPa) & (hrs) & (hrs) & (hrs) & (\%) & (C) & (MPa) & (hrs) & (hrs) & (hrs) & (\%) \\
\hline No bound. & 760 & 690 & 18.7 & 49.0 & 160.5 & 13.9 & 982 & 207 & 14.6 & 24.0 & 43.6 & 15.7 \\
\hline No bound. & 760 & 690 & 30.0 & 66.0 & 187.8 & 13.8 & & & & & & \\
\hline No bound. & 760 & 690 & 35 & 77 & 176.2 & 12.6 & & & & & & \\
\hline 6.2 & 760 & 690 & 18.5 & 54.0 & 171.1 & 11.7 & 982 & 207 & 7.5 & 14.0 & 35.2 & 20.9 \\
\hline 6.2 & 760 & 758 & 2.1 & 8.0 & 36.3 & 11.3 & 982 & 207 & 7.4 & 14.8 & 33.9 & 16.0 \\
\hline 6.2 & 760 & 758 & 1.0 & 4.7 & 35.9 & 15.8 & 982 & 152 & 85.0 & 165 & 287 & 17.6 \\
\hline 6.2 & 760 & 690 & 16.8 & 47 & 143.2 & 13.0 & 982 & 172 & 40.0 & 62 & 101.3 & 16.8 \\
\hline 13.7 & 760 & 690 & 26.0 & 59.0 & 117.6 & 5.5 & 982 & 207 & 10.1 & 18 & 33.1 & 9.2 \\
\hline 13.7 & 760 & 724 & 6.9 & 151.7 & 54.8 & 5.2 & 982 & 152 & 67.0 & 131 & 220.8 & 7.3 \\
\hline 13.7 & 760 & 690 & 16.7 & 48.0 & 134.1 & 7.5 & 982 & 172 & 26.9 & 52.0 & 82.2 & 6.9 \\
\hline 13.7 & 760 & 724 & 5.1 & 18.1 & 55.9 & 6.5 & 982 & 172 & 34.0 & 63.0 & 112 & 8.5 \\
\hline 21.2 & 760 & 414 & - & - & +4078.1 & 0.0 & & & & & & \\
\hline 21.2 & 760 & 552 & 388 & 814 & 1442.6 & 4.9 & 982 & 207 & 13.8 & 24.0 & 30.4 & 4.2 \\
\hline 21.2 & 760 & 690 & 34.0 & 69.0 & 90.7 & 3.2 & 982 & 172 & 44.0 & 67.0 & 69.6 & 3.2 \\
\hline
\end{tabular}

+ Discontinued, no failure

Thus yield strength can be linearly related to critical resolved shear strength $\left(\tau_{c}\right)$ by the relation

$$
\sigma_{y}=\tau_{c} \sqrt{ } 6\left(1-0.0149 \alpha^{\circ}\right)
$$

In Fig. 2, the $0.2 \%$ yield strength data reasonably fits this description, if it is assumed that $\tau_{\mathrm{c}}=445 \mathrm{MPa}$. Also plotted in Fig. 2, for comparison, are tensile data for Modified PWA1483 at $6.5^{\circ}$. It is evident that while there is little change in UTS, $0.2 \%$ yield strength is significantly reduced for the modified alloy. 
Creep: As noted earlicr, in all cases, except at $760^{\circ} \mathrm{C} / 793 \mathrm{MPa}$, creep rupture life and time to $2 \%$ decrease with increasing deviation of $\alpha$ from $<001>$. The rate of decrease in rupture life was observed to be much higher than that for time to $2 \%$ creep. A Larson-Miller plot of the data, presented in Fig.5, depicts this trend in rupture life. In the figure, rupture life data at $\alpha=10^{\circ}$ and $\alpha=25^{\circ}$ are compared. Based on this plot a decrease of 207 in L-M parameter is determined, for increasing $\alpha$ from $10^{\circ}$ to $25^{\circ}$. This translates into a $35 \%$ drop in rupture life at constant stress, or a $8^{\circ} \mathrm{C}$ temperature debit for the same creep strength, or a $30-40$ $\mathrm{MPa}$ drop in creep strength, at the same temperature. Obviously, the decrease in creep capability will be less significant if time to $2 \%$ data were compared in Fig. 5 . It is interesting to note that the loss in creep strength with a $15^{\circ}$ deviation in primary orientation is comparable to the loss in creep-strength for the modified alloy with respect to PWA1483.

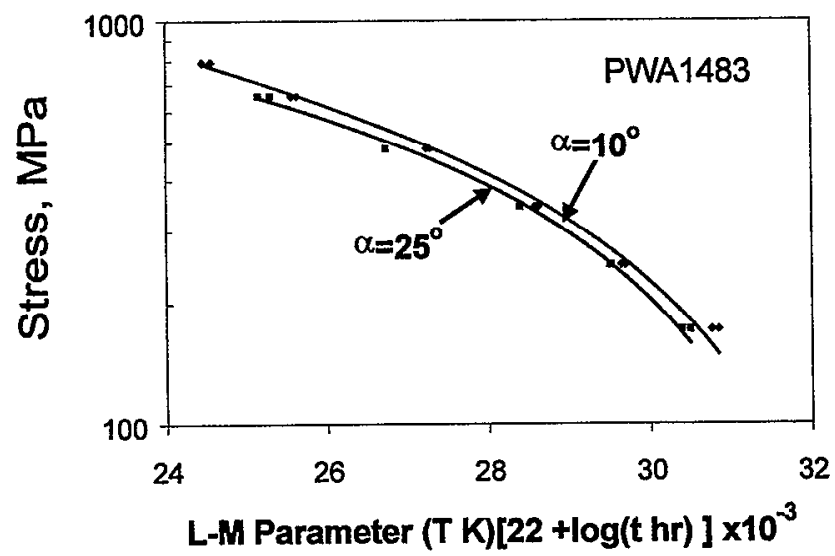

Figure 5: Larson-Miller comparison of creep rupture life of PWA1483 with primary orientation deviations $(\alpha)$ of $10^{\circ}$ and $25^{\circ}$.

\section{Grain Boundary Tolerance}

From $\log -\log$ plots of stress vs. rupture life, stress for rupture in $100 \mathrm{hrs}$ was determined for PWA1483 and Modified PWA1483, respectively, at $760^{\circ} \mathrm{C}$ and $982^{\circ} \mathrm{C}$, for various grain boundary misorientations. The results are depicted in Fig. 6, as a plot of stress for 100-hr rupture, versus grain boundary misorientation for both alloys at both temperatures. Note that while the stress drops precipitously for grain boundary misorientations greater than $10^{\circ}$ for PWA1483, there is virtually no change in the case of Modified PWA1483. In fact, as reported in Table IV, testing of a specimen cast in Modified PWA1483 was discontinued at $760^{\circ} \mathrm{C} / 414 \mathrm{MPa}$, after 4078 hours. The results clearly suggest that additions of minor elements, boron and hafnium, in the Mod. PWA1483, has significantly increased its tolerance to grain boundary type defects. It is apparent from Fig. 6, that there is aimost a $50 \%$ debit in stress capability for PWA1483 $\left(760^{\circ} \mathrm{C}\right)$ with $\mathrm{HAB}$ greater than $20^{\circ}$. However, for the Modified PWA1483 alloy, HABs do not significantly debit creep strength.

Stress debit is not the only measure of the impact of grain boundary type defects. Total clongation at failure is another measure of margin of safety in engineering applications. Creep rupture elongation measured after failure for both PWA1483 and
Modified PWA1483, are plotted against grain boundary misorientation in Fig. 7. The elongation data at $760^{\circ} \mathrm{C}$ and $982^{\circ} \mathrm{C}$ for each alloy follow the same trend with grain boundary misorientation, and hence only one trend line is shown for each alloy. Note that even in the presence of a high angle boundary defect, the modified alloy exhibits ductility greater than $2 \%$, compared to virtually none $(<0.2 \%)$ in the base alloy. It is evident that addition of minor elements not only improves the stress capability, but also enhances ductility in the presence of HABs.

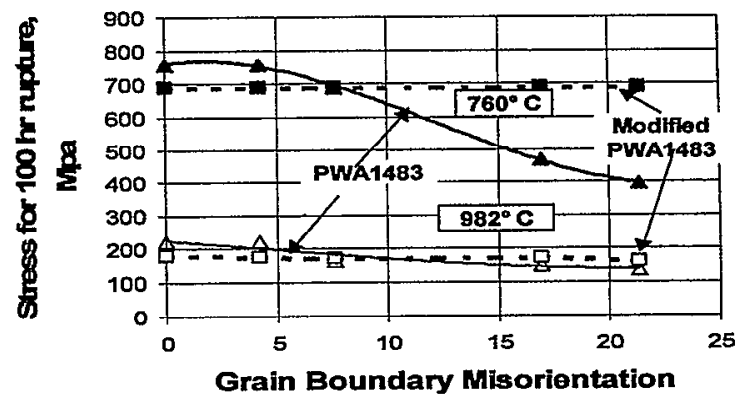

Figure 6: Stress for $100 \mathrm{hr}$ rupture versus grain boundary misorientation at $760^{\circ} \mathrm{C}$ and $982^{\circ} \mathrm{C}$ for PWA1483 and Modified PWA1483.

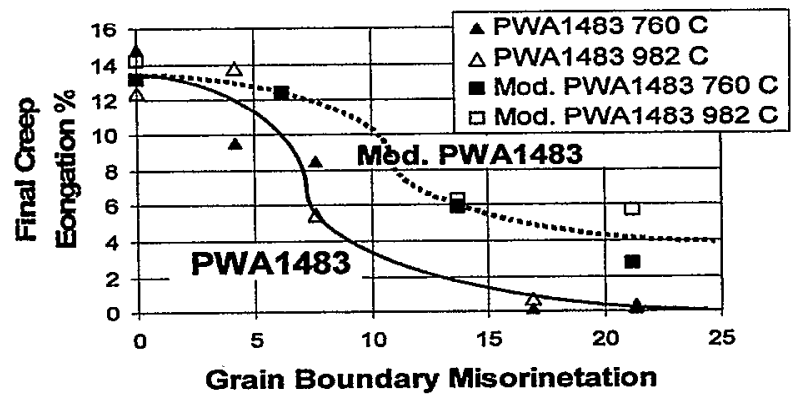

Figure 7: Creep rupture elongation at $760^{\circ} \mathrm{C}$ and $982^{\circ} \mathrm{C}$, versus grain boundary misorientation for PWA1483 and Modified PWA1483. Trend in ductility behavior is almost identical at both temperatures.

While our results, on improving grain boundary tolerance with additions of $\mathrm{B}$ and $\mathrm{Hf}$, is not totally surprising, the robust tolerance to $\mathrm{HAB}$ as large as $20^{\circ}$, is not in agreement with past experience. Ross and O'Hara [8], in their study of the alloy Rene N4, concluded that addition of minor elements at low level, enhance the grain boundary tolerance to $12^{\circ}$. Past testing of columnar grain alloys such as PWA1422, in transverse orientation, has always shown a significant creep strength debit in spite of even greater additions of minor elements. We shall return to this aspect later in the discussion.

As alluded to earlier, for alloys without minor elements, the tolerance to grain boundaries with $6-10^{\circ}$ misorientation, coincides with a steep increase in grain boundary diffusion. This implies that without the minor elements, grain boundary failure may be further aggravated by environmental interactions. In the presence of minor elements, this aspect is largely mitigated. Thus, once the minor elements are added, the loss of creep strength may not originate entirely from the grain boundary per se, but may be 
dependent on transgranular creep behavior. Transgranular creep deformation is obviously controlled by the orientation dependence of creep behavior, as well as deformation compatibility in the vicinity of the grain boundary.

Role of Primary Orientation: When a bicrystal is tested in creep, with the grain boundary oriented normal to the stress axis, the grain boundary misorientation alone is not sufficient to define the creep behavior, especially for high angle boundaries. For example, a $20^{\circ}$ bicrystal can be produced with a pure twist boundary with both grains oriented along either a $\langle 100\rangle$ or $<110\rangle$ direction. Alternatively, a $20^{\circ}$ tilt boundary can be produced with the orientation of each grain approximately $10^{\circ}$ away from $\langle 100\rangle$, or one grain close to $\langle 100\rangle$, and the other off by $20^{\circ}$ from $\langle 100\rangle$. Since the latter case was the way bicrystals were produced for this study, it is expected that creep properties will, as a minimum, degrade as the primary orientation of one of the crystal shifts away from $\langle 100\rangle$.

To assess this effect, $760^{\circ} \mathrm{C} / 690 \mathrm{MPa}$ rupture life is plotted in Fig. 8 for both bicrystals and off-axis specimens. Note that for PWA1483 bicrystals, the grain boundary misorientation obviously dominates. However, in the case of Mod. PWA1483, the inverse relation observed with grain boundary misorientation, is similar to the trend observed between rupture life and primary orientation for PWA1483. At $982^{\circ} \mathrm{C} / 30 \mathrm{MPa}$, the misorientation relationship for the Mod. PWA1483 follows the same trend as primary orientation for PWA1483, although the PWA1483 rupture lives are consistently higher, as shown Fig. 9. This difference in creep strength is consistent with the creep-rupture comparison of both alloys $\left(\alpha=6^{\circ}\right)$ presented in Fig. 3 .

The data for both alloys ( $\mathrm{LAB}<6^{\circ}$ and HAB $6-20^{\circ}$ ) is also compared on plots of stress vs. rupture life at 760 and $982^{\circ} \mathrm{C}$ (Figs. 10 and 11). At both test temperatures, PWA1483 creep strength is significantly debited by $\mathrm{HAB}$, while the modified alloy shows much less of an effect. Even though the modified alloy has lower absolute creep-strength capability than PWA1483, the modified alloy shows a large advantage when comparisons are made with material containing HAB. As shown in Figs. 10 and 11 , in material containing $\mathrm{HAB}$, the modified alloy shows more than a $50 \%$ stress advantage at $760^{\circ} \mathrm{C}$, and an $\sim 10 \%$ stress advantage at $982^{\circ} \mathrm{C}$, over PWA1483.

Role of $<110\rangle$ orientation: In a $<100>$ oriented single crystal component, at least two secondary directions in the transverse plane will always coincide with $\langle 110\rangle$. This is known to be the weakest direction in creep, although single crystal components are used in practice in spite of that. The question is, whether a $20^{\circ}$ boundary with $\langle 110\rangle$ orientation would have performed as well. Unfortunately, no creep data were generated in $\langle 110\rangle$ oriented $\mathrm{PW}$ 1483. However, if past results were any guide, rupture life would be expected to be very low. If $20^{\circ}$ bicrystals were grown with average grain orientations near $\langle 110\rangle$, chances are that creep results would have been poor. This may represent the worst condition, similar to columnar grain material tested in a transverse direction. However, the key question is whether transverse properties are always poor because of the presence of grain boundaries or because of crystal orientation.

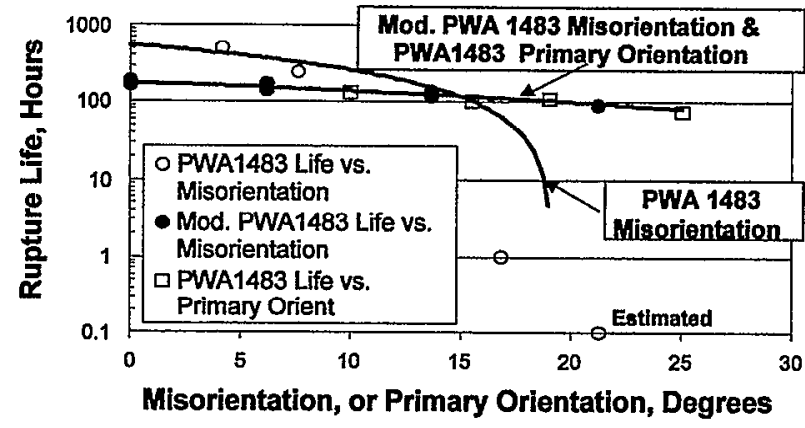

Figure 8: $760^{\circ} \mathrm{C} / 690 \mathrm{MPa}$ creep-rupture life of PWA1483 and Mod.PWA1483 vs. grain boundary misorientation, and primary orientation.

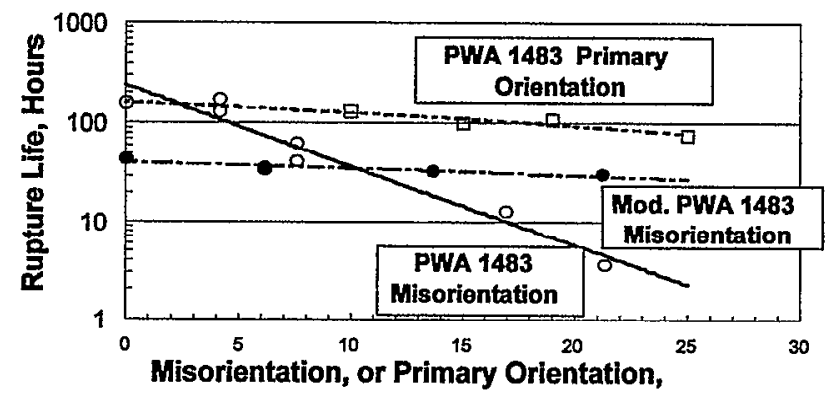

Figure 9: $982^{\circ} \mathrm{C} / 30 \mathrm{MPa}$ creep-rupture life of PWA1483 and Mod.PWA1483 vs. grain boundary misorientation and primary misorientation.

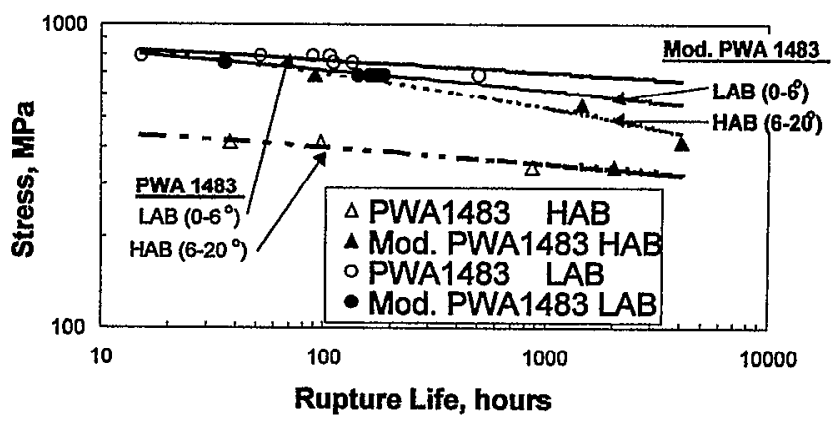

Figure 10: Effect of $\mathrm{HAB}$ on $760^{\circ} \mathrm{C}$ creep-rupture life of PWA1483 vs. Mod. PWA1483.

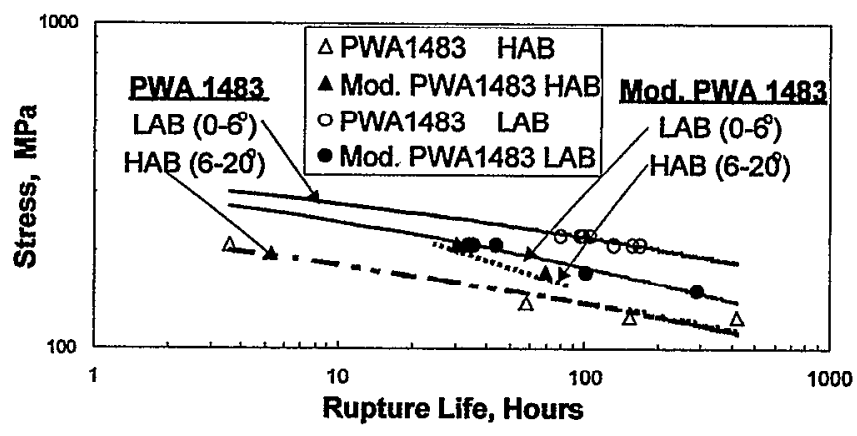

Figure 11: Effect of $\mathrm{HAB}$ on $982^{\circ} \mathrm{C}$ creep-rupture life of PWA1483 vs. Mod. PWA1483. 
To answer this question, we revisited results for Mar M200+Hf, for which data in both columnar grain, and single crystal [4], form were available.

Mar M200 Experience: $760^{\circ} \mathrm{C}$ creep-rupture life for Mar M200+Hf, for columnar grain (CG) material in longitudinal and transverse directions, and single crystal material in $\langle 100\rangle$ and $<110>$ orientations, is presented Fig. 12. Linear parallel extrapolation is used to compare data for different orientations generated at different stresses. Clearly the wide scatter in data for the transverse orientation spans the range from the lowest rupture life for $\langle 100\rangle$, down to lower than $\langle 110\rangle$ orientated single crystals. If what we have observed for Mod.PWA1483 were true for Mar M200+Hf, the large scatter in rupture life in the transverse orientation must be a consequence of the uncontrolled nature of primary orientation of grains in a transverse specimen. This suggests that there may be nothing unique about high $\mathrm{Cr}$ containing Mod.PWA1483. The high tolerance to grain boundary misorientation, may be a result of testing $\langle 100\rangle$-oriented bicrystals. Evaluation of HAB bicrystals with $\langle 110\rangle$ primary orientation is needed to define the worst case scenario.

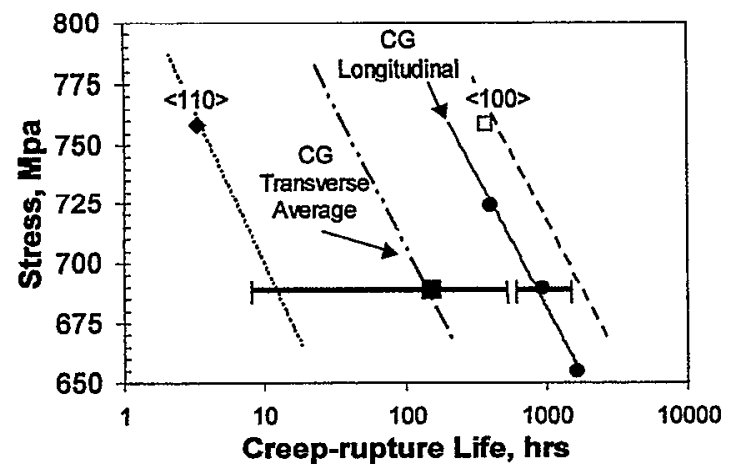

Fig. 12: Transverse $760^{\circ} \mathrm{C}$ creep-rupture life for columnar grain Mar M200+Hf spans range between longitudinal and $<110>$ single crystal data at $690 \mathrm{MPa}$.

\section{Summary}

1. High growth rate seems to be helpful in suppressing grain boundary type defccts as well as dendrite splaying in large single crystal castings. At the current development of casting technology, no significant difference in behavior of castable single crystal alloys could be discerned.

2. As expected, both low temperature tensile and high temperature creep strength of PWA1483 decrease with increasing deviation from the primary $<001>$ direction.

3. Tolerance to high angle grain boundaries is significantly improved with minor element additions in creep at all temperatures. However, a creep strength debit is associated with this benefit at high temperatures.

4. In spite of a creep strength improvement with minor element additions, in the presence of high angle grain boundaries, creep ductility is limited compared to defect-free single crystal.

5. Comparison with data for Mar M200+Hf, suggests that the observed exceptional tolerance to high angle grain boundaries with minor element additions, may be a result of the $<100>$ orientation of the bicrystals evaluated.

6. Evaluation of $\langle 110\rangle$ oriented high angle boundaries is necessary to assess the true benefit of addition of minor elements to single crystal alloys for improving tolerance to occasional grain boundary type defects.

7. With improvement in casting technology and better understanding of material behavior, and design tradeoffs, application of single crystal technology for large IGT seems economically viable.

\section{Acknowledgement}

Thanks are due to Mr. Allan Price of Howmet Research Corporation for supply of single crystal castings. Many thanks are due to Mr. Glenn Cotnoir of P \&W for technical help.

\section{References}

1. R. P. Dalal, C. R. Thomas, and L. E. Dardi, "The Effect of Crystallographic Orientation on the Physical and Mechanical Properties of an Investment Cast Single Crystal Nickel-Base Superalloy" (SUPERALLOYS 1984, Edited by M. Gell, et al., TMS-AIME, Warrandalc, PA., 1984) 185.

2. D. N. Duhl in Superalloys, Supercomposites, and Superceramics, (Edited by J. K. Tien and T. Caulfield, Academic Press, Boston) 149.

3. R. A. MacKay, R. L. Dreshfield, and R. D. Maier, "Anisotropy of Nickel-Base Superalloy Single Crystals" (SUPERALLOYS 1980, Edited by J. K. Tien et al., ASM, Metals Park, Ohio, 1980, p.385.

4. D. M. Shah and D. N. Duhl, "The Effect of Orientation, Temperature and Gamma Prime Size on the Yield Strength of a Single Crystal Nickel Base Superalloy" (SUPERALLOYS 1984, Edited by M. Gell et al., TMS-AIME, Warrandale, PA., 1984) 105.

5. D. M. Shah and A. Cetel, "Creep Anisotropy in Nickel Base $\gamma, \gamma^{\prime}, \gamma / \gamma^{\prime}$ Superalloy Single Crystals" (SUPERALLOYS 1996, Edited by R. D. Kissinger et al., TMS, Warrandale, PA) 273.

6. D. M. Shah and D. N. Duhl, "Effect of Minor Elements on the Deformation Behavior of Nickel-Base Superalloys" (SUPERALLOYS 1988, Edited by D. N. Duhl et al., TMSAIME, Warrandale, PA., 1988) 693.

7. Shewman, Paul G., Diffusion in Solids, McGraw-Hill, New York, 1963, p.173.

8. E. W. Ross and K. S. O'Hara, "René N4: A First Generation Single Crystal Turbine Airfoil Alloy With Improved Oxidation Resistance, Low Angle Boundary Strength and Superior Long Time Rupture Strength" (SUPERALLOYS 1996, Edited by R. D. Kissinger et al., TMS, Warrandale, PA) 19. 